\title{
Airway Obstruction Caused by Sputa in Heat and Moisture Exchange Filter During Ventilation Using Supra-Laryngeal Mask Airway: A Case Report
}

\author{
Naoya Kobayashi ${ }^{1}$, Masanori Yamauchi ${ }^{1}$
}

\section{Abstract}

Introduction: Supra-laryngeal mask airway (LMA) is widely accepted as an alternative to the tracheal tube. However, compared to the use of a tracheal tube, it may take longer to identify the many different causes of sudden respiratory distress. In particular, heat and moisture exchange filters are one of the most overlooked causes.

Case presentation: The case was that of a 76-year-old male Japanese patient $(161.9 \mathrm{~cm}, 66.5 \mathrm{~kg})$ who underwent an open renal biopsy. He presented with chronic obstructive pulmonary disease, with a Hugh-Jones dyspnea score of 2 . The patient did not discontinue smoking prior to the operation. Anesthesia was induced using propofol $(100 \mathrm{mg})$, fentanyl $(100 \mu \mathrm{g})$, and remifentanil $(0.3 \mu \mathrm{g} / \mathrm{kg} / \mathrm{min})$. I-gel ${ }^{\mathrm{m} \mathrm{m}} \# 4$ was inserted following neuromuscular blockade with rocuronium $(40 \mathrm{mg})$. Anesthesia was maintained with 3-6\% desflurane under positive pressure ventilation. After induction in the left lateral and jackknife positions, the following ventilator settings were used: volume-controlled ventilation with tidal volumes of $450 \mathrm{~mL}$, respiratory rate of 12 breaths per minute, an inspiratory:expiratory ratio of 1:2, and a positive end expiratory pressure of $5 \mathrm{~cm} \mathrm{H}_{2} \mathrm{O}$. With these settings, the peak inspiratory pressure was $16 \mathrm{~cm} \mathrm{H}_{2} \mathrm{O}$. Five minutes after initiating the operation, the peak inspiratory pressure steadily increased to $30 \mathrm{~cm} \mathrm{H}_{2} \mathrm{O}$. Although we administered rocuronium, the peak inspiratory pressure and end-tidal carbon dioxide concentration increased over time. When we disconnected the heat and moisture exchange filter and LMA, we noticed a large quantity of sputa. A suction catheter was passed down the LMA and the sputa was removed, but the LMA was not obstructed. The peak inspiratory pressure continued to increase with tidal volumes of only 20-30 mL. Despite a normal external appearance of the heat and moisture exchange filter, we replaced it with a new one. The ability to ventilate improved immediately and the $\mathrm{SpO}_{2}$ recovered from $92 \%$ to $100 \%$.

Conclusions: A heat and moisture exchange filter obstruction can be fatal during the usage of LMA. A combination of factors caused delays in the diagnosis.

Keywords: Airway obstruction, Heat and moisture exchange filter, Mechanical ventilation

\section{Background}

LMA were introduced in the 1980s and gained wide acceptance as alternatives to tracheal tubes. I-gel ${ }^{\mathrm{Tw}}$ (Intersurgical Ltd, Workingham, $\mathrm{UK}$ ) is a disposable Supra-laryngeal device with a non-inflatable cuff composed of thermoplastic elastomer gel that eliminates the need for cuff inflation and therefore prevents potential complications related to high intra-cuff pressures. In addition, it has a symmetrical, widened, elliptical, and laterally flattened stem, which may facilitate easier insertion and improved stabilization during maintenance of anesthesia. Since then, it has gained popularity for airway management in both anesthesia and resuscitation owing to its ease of use [1-4]. However, compared to the use of a tracheal tube, it may take longer to identify the many different causes of sudden respiratory distress. While a wide variety of causes must be considered, including patient factors such as tracheal obstruction due to sputum, asthma, and laryngospasm, and mechanical factors such as device malposition, leaks, and ventilator problems, the time allowed between unventilated and ventilated is only a few minutes at most. Heat and moisture exchange filters (HMEF) are particularly dangerous because they are one of the most overlooked causes and can be too late if the blockage is noticed after other causes have been considered.

\section{Case Presentation}

We present a case of unexpected airway obstruction due to the occlusion of an HMEF by a large quantity of serous sputa. The case was that of a 76-year-old male patient $(161.9 \mathrm{~cm}, 66.5 \mathrm{~kg})$ who underwent an open renal biopsy for a more detailed examination of chronic renal failure. He presented with hypertension and chronic obstructive pulmonary disease, with a Hugh-Jones dyspnea score of [2]. The patient did not discontinue smoking prior to the operation. Written consent for publication was obtained from the patient. Anesthesia was induced using propofol $(100 \mathrm{mg})$, fentanyl (100 $\mu \mathrm{g})$, and remifentanil $(0.3 \mu \mathrm{g} \bullet \mathrm{kg}-1 \bullet \mathrm{min}-1)$. I-gel ${ }^{\bullet} \# 4$ was inserted following neuromuscular blockade with rocuronium $(40 \mathrm{mg})$. Anesthesia was maintained with 3-6\% desflurane under positive pressure ventilation. A gastric tube ( $8 \mathrm{Fr})$ was inserted through the drainage port of the LMA. After induction in the left lateral and jackknife positions, the following ventilator settings were used: volume-controlled ventilation

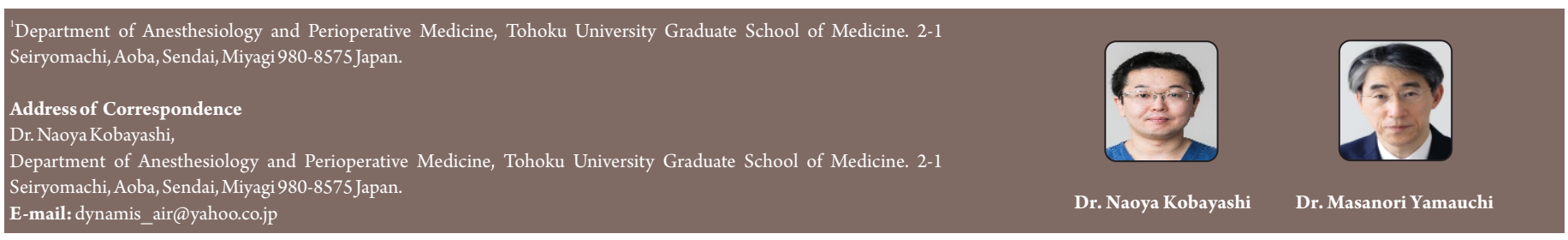

Submitted: 31/3/2021; Reviewed: 12/5/2021; Accepted: 1/8/2021; Published: 10/9/2021

DOI: 10.13107/jaccr.2021.v07i03.184

This is an Open Access journal, and articles are distributed under the terms of the Creative Commons Attribution Non-Commercial-Share Alike 4.0 License (http://creativecommons.org/licenses/by-nc-sa/4.0) which allows others to remix, tweak, and build upon the work non-commercially as long as appropriate credit is given and the new creation are licensed under the identical terms. 
with tidal volumes (TVs) of $450 \mathrm{~mL}$, respiratory rate of 12 breaths per minute, an inspiratory:expiratory ratio of $1: 2$, and a positive end expiratory pressure of $5 \mathrm{~cm} \mathrm{H}_{2} \mathrm{O}$. With these settings, the peak inspiratory pressure (PIP) was $16 \mathrm{~cm} \mathrm{H}_{2} \mathrm{O}$. Five minutes after initiating the operation, the PIP steadily increased to $30 \mathrm{~cm} \mathrm{H}_{2} \mathrm{O}$. Because a sudden laryngospasm was suspected, rocuronium $(25 \mathrm{mg})$ was administered and the ventilator settings were changed from volume-controlled to pressure-controlled ventilation with a PIP of 35 $\mathrm{cm} \mathrm{H}_{2} \mathrm{O}$. Although we administered rocuronium, the PIP and endtidal carbon dioxide concentration increased over time. Upon bilateral auscultation of the chest, normal breath sounds were heard. The circle system was disconnected from the HMEF (DAR Hygrobag-S ${ }^{\circledR}$; Covidien, Tokyo, Japan; dead space of $45 \mathrm{~mL}$, recommended tidal volume of $150-1200 \mathrm{~mL}$ ) and found to be functioning normally, thereby excluding mechanical obstruction upstream of the HMEF as a cause of elevated PIP. When we disconnected the HMEF and LMA, we noticed a large quantity of serous sputa on the patient-side of the LMA. A suction catheter was passed down the LMA and the sputa was removed, but the LMA was not obstructed. The PIP continued to increase with tidal volumes of only $20-30 \mathrm{~mL}$. Despite a normal external appearance of the HMEF, it was replaced with a new HMEF. The ability to ventilate improved immediately with a PIP of $16 \mathrm{~cm}$ $\mathrm{H}_{2} \mathrm{O}$ that resulted in a TV of $480 \mathrm{~mL}$ and recovery of the $\mathrm{SpO}_{2}$ from $92 \%$ to $100 \%$. The time from PIP elevation to $\mathrm{SpO}_{2}$ recovery was about 10 minutes. The patient did not develop neurological abnormalities and was fully awake after the operation.

\section{Discussion}

The main causes of dyspnea when using LMA are considered to be the following.

The first is a laryngospasm, which causes a complete obstruction of the upper airway and can lead to oxygen desaturation, negative pressure pulmonary edema, and death [5]. The spasm is caused by strong external stress, such as surgery or intubation. As treatment, a muscle relaxant is effective. However, in our patient, rocuronium was not effective.
The second is accidental swallowing. Patients who undergo the insertion of LMA experience more accidental swallowing than intubated patients. Although accidental swallowing occurred, complete airway obstruction hardly occurred after suction. In this case, we were still unable to ventilate despite the secretions being suctioned out completely.

The third factor is the abnormal position of the LMA. Head and neck movements change the shape of the pharynx [6]; this can displace the LMA and cause peri-laryngeal leakage with changes in head positions [7]. When respiration is compromised, we must change the LMA to a tracheal tube.

However, the cause of airway obstruction in our case was the fourth cause, which was sputa reaching the HMEF and obstructing it. if we had converted to intubation, we might not have been able to ventilate and the patient would have experienced serious hypoxia.

Airway obstruction due to sputum often occurs with tracheal tubes [811], but is considered rare with LMA. In particular, if phlegm reaches the HMEF, the filter may take a long time to deal with, as it becomes irreversibly blocked and must be replaced. An obstruction of the HMEF is likely to occur when the patient is in the lateral or prone position due to reversed flow of the secretions. When these positions are used with LMA, we recommend being cautious about airway obstructions and considering the possibility of HMEF obstruction. This is one of the basic troubleshooting steps, but like checking vital signs (12], it must be checked because it directly affects the life of the patient.

In conclusion, an HMEF obstruction can be fatal during the usage of LMA. It is important to consider HMEF malfunction because troubleshooting requires multiple steps.

Declaration of patient consent: The authors certify that they have obtained all appropriate patient consent forms. In the form, the patient has given his consent for his images and other clinical information to be reported in the Journal. The patient understands that his name and initials will not be published, and due efforts will be made to conceal his identity, but anonymity cannot be guaranteed.

\section{Conflict of interest: Nil Source of support: None}

\section{References}

1. Lee JR, Kim MS, Kim JT, Byon HJ, Park YH, Kim HS, et al. A randomised trial comparing the i-gel (TM) with the LMA Classic (TM) in children. Anaesthesia. 2012;67(6):606-11.

2. Beringer RM, Kelly F, Cook TM, Nolan J, Hardy R, Simpson T, et al. A cohort evaluation of the paediatric i-gel() airway during anaesthesia in 120 children. Anaesthesia. 2011;66(12):1121-6.

3. Kim MS, Oh JT, Min JY, Lee KH, Lee JR. A randomised comparison of the i-gel and the Laryngeal Mask Airway Classic in infants. Anaesthesia.2014;69(4):362-7.

4. Kobayashi N, Wagatsuma T, Shiga T, Toyama H, Ejima Y, Yamauchi M. Age-related changes in factors associated with delayed extubation after general anesthesia: a retrospective study.JA Clin Rep.2020;6(1):20.

5. Cavallone LF, Vannucci A. Review article: Extubation of the difficult airway and extubation failure. Anesth Analg. 2013;116(2):368-83.

6. Nandi PR, Charlesworth CH, Taylor SJ, Nunn JF, Dore CJ. Effect of general anaesthesia on the pharynx. BrJ Anaesth. 1991;66(2):157-62.

7. Woo YC, Cha SM, Kang H, Baek CW, Jung YH, Kim JY, et al. Less perilaryngeal gas leakage with SLIPA than with LMA-ProSeal in paralyzed patients. Can J Anaesth. 2011;58(1):48-54.

8. Lawes EG. Hidden hazards and dangers associated with the use of HME/filters in breathing circuits. Their effect on toxic metabolite production, pulse oximetry and airway resistance. $\mathrm{Br} \mathrm{J}$ Anaesth. 
2003;91(2):249-64.

9. Stacey MR, Asai T, Wilkes A, Hodzovic I. Obstruction of a breathing system filter. Can J Anaesth. 1996;43(12):1276.

10. Reddy SC, Lim E. Unexpected airway obstruction due to oversaturation of a heat and moisture exchange filter. Anaesth Intensive Care. 2017;45(2):274.
11. Kobayashi N, Ando K, Saito K, Toyama H, Fudeta H, Yamauchi M. Awake Nasotracheal Intubation for a 4-Year-old Boy with an Oral Penetrating Toothbrush Injury. Masui. 2015;64(9):981-4.

12. Kobayashi N, Shiga T, Ikumi S, Watanabe K, Murakami H, Yamauchi M. Semi-automated tracking of pain in critical care patients using artificial intelligence: a retrospective observational study. Sci Rep. 2021;11(1):5229.

\section{How to Cite this Article}

Kobayashi N, Yamauchi M | Airway Obstruction Caused by Sputa in Heat and Moisture Exchange Filter During Ventilation Using Supra-Laryngeal Mask Airway: A Case Report | Journal of Anaesthesia and Critical Care Case Reports | SeptemberDecember 2021; 7(3): 07-09. 